16 are in part responsible for $\mathrm{T}$ cell abnormalities in SLE patients.

Objectives To investigate whether increased levels of IL-16 is a characteristic underlying susceptibility to SLE or is a characteristic of the disease itself.

Methods Accumulated organ damage was measured with the SLICC/ACR Damage Index. Twenty-five severe (SLICC/ACR: $4.9+2.5$ ) and ten non-severe (SLICC/ACR: $1.0+0.8)$ SLE patients were included in this study. Also 11 first degree relatives and 12 healthy volunteers were included in this study. Plasma IL-16 levels were measured by ELISA.

Results No significant difference in the IL-16 levels of the first degree relatives of patients with SLE $(38.3+11.1 \mathrm{pg} / \mathrm{ml})$ were observed when compared to controls $(31.2+10.1 \mathrm{pg} / \mathrm{ml})$. In order to analyse characteristics of the SLE in relation to concentration of IL-16, IL-16 was measured in severe SLE patients $(71.3+87.4 \mathrm{pg} / \mathrm{ml} ; \mathrm{P}=0.025)$ compared to healthy controls. On the other hand, no significant differences were observed between the non-severe SLE patients $(37.8+26.1 \mathrm{pg} / \mathrm{ml})$ and controls.

Conclusion No evidence for increased IL-16 levels in first degree relatives of the SLE patients was observed. IL-16 is enhanced in SLE patients with a severe disease, but not in patients with nonsevere disease, thereby suggesting that IL-16 is associated with disease severity, and not with susceptibility for SLE.

\section{FRI0084 AUTOPSY REPORTS OF THE CEREBRUM OF 24 PATIENTS WITH SLE IN THE PERIOD 1988-99}

CF Allaart, MJ Rood, SG Van Duinen, TW Huizinga. Rheumatology, Leiden University Medical Center, Leiden, The Netherlands

\subsection{6/annrheumdis-2001.1226}

Background Clinical manifestations of neurologic involvement in patients with SLE (Neuropsychiatric SLE or NPSLE) may be either due to secundary causes such as antiphospholipid-syndrome associated infarctions or bleedings or infections, or due to primary causes such as immune-mediated vasculitis or cerebritis. Depending on the probable cause, different therapeutic approaches are chosen.

Objectives Previous reports on histopathologic have suggested that, since it is so seldomly found, cerebral vasculitis cannot be an important cause of neurologic symptoms in SLE.

\section{Methods}

Results However, a search in the computer archives of PALGA, the foundation that collects all pathology reports from Dutch PA-laboratories, beginning in 1988 and covering all reports since 1990, revealed vasculitis laesions in no less than 5 of 24 cranial autopsies of patients with SLE. In an additional 4, laesions were described that were compatible with remnants of previous vasculitis.

Abstract FRI0084 Table 1 Conclusions of autopsy reports of 24 consecutive patients with SLE in the medical history and a cranial autopsy report

\begin{tabular}{ll}
\hline Primary NPSLE & 7 \\
Secundary NPSLE & 9 (4 bleeding, 5 infection) \\
Other causes & 6 \\
No abnormalitiesInsufficient information & 1 \\
Insufficient information & 1 \\
\hline
\end{tabular}

Conclusion These findings suggest that cerebral vasculitis must be considered as a possible underlying cause of symptoms when it comes to choosing therapy for patients with NPSLE.

\section{FRI0085 ANTI-BETA-2- GLYCOPROTEIN I ANTIBODIES IN SYSTEMIC LUPUS ERYTHEMATOSUS PATIENTS}

AG Borodin, EL Nassonov, AA Baranov, NG Klukvina. Department of Therapy, Medical Academy, Yaroslavl, Russia, Yaroslavl, Russia

10.1136/annrheumdis-2001.1227

\section{Background}

Objectives

Methods Anticardiolipin antibodies (aCL) react with negatively charged phospholipids, which may often be complexed with a protein cofactor such as beta-2-glycoprotein I.

Results To obtain information about the prevalence and levels of IgG anti-â2-GPI, IgG- and IgM-aCL in systemic lupus erythematosus (SLE) patients (pts) these antibodies were measured, by an enzyme linked immunosorbent assay, in sera from 147 pts with SLE (70 men and 77 women). The results were compared with 20 healthy subjects. Anti-â2-GPI were found positive (more than 3 s.d. above the mean in normal controls) in 15 females $(19,4 \%)$, 14 males $(20 \%)$ in pts with SLE compared to 1 person $(5 \%)$ in normal controls. $48,3 \%$ of pts with anti-â2-GPI had the history of thrombosis, compared with $11,02 \%$ of pts without anti-â2GPI ( $p<0,001) .35,7 \%$ of females with anti-â2-GPI had the history of fetal loss, in comparison with $6,56 \%$ of anti-â2-GPI negative pts.

APS was diagnosed in $16(69,56 \%)$ anti-â2-GPI $(+)-\mathrm{aCL}(+)$ pts $(\mathrm{n}=23)$ and in $15(37,5 \%)$ anti-â2-GPI $(-)-\mathrm{aCL}(+)$ pts $(\mathrm{n}=$ 40) $(\mathrm{p}<0,01)$. Anti-â2-GPI $(+)-\mathrm{aCL}(+)$ pts had a history of thrombosis more frequently $(\mathrm{n}=14,60,86 \%)$ than anti-â2-GPI $(+)-\mathrm{aCL}(-)(\mathrm{n}=6)(\mathrm{n}=0,0 \%, \mathrm{p}<0,002)$.

Our data show that the presence of anti-â2-GPI simultaneously with aCL is strong associated with APS in SLE.

Conclusion

\section{FRI0086 CHARACTERISATION OF RA33 (HNRNP-A2/B1)- AUTOREACTIVE T CELLS IN SLE-PATIENTS}

${ }^{1} \mathrm{R}$ Fritsch, ${ }^{1} \mathrm{D}$ Eselboeck, ${ }^{2} \mathrm{~B}$ Jahn-Schmid, ${ }^{3} \mathrm{~J}$ Neumueller, ${ }^{2} \mathrm{~B}$ Bohle, ${ }^{1} \mathrm{~K}$ Skriner, ${ }^{1} \mathrm{~J}$ Smolen, ${ }^{1} \mathrm{G}$ Steiner. 'Department of Rheumatology; ${ }^{2}$ Department of Pathophysiology, AKH (General Hospital) -Wien; ${ }^{3}$ Institute of Histology, University of Vienna, Vienna, Austria

\subsection{6/annrheumdis-2001.1228}

Background SLE is a systemic autoimmune disease with distinct immunological characteristics including defective $\mathrm{T}$ cell functions, especially concerning IL2 production and proliferation. Furthermore, B-cell hyperactivity is observed leading to the formation of several characteristic autoantibodies (ab), among them $\mathrm{ab}$ to the heterogenous nuclear ribonucleoprotein A2/B1 (hnRNP/RA33). These antibodies are known to occur in over $20 \%$ of SLE patients.

Objectives In order to elucidate the role of $\mathrm{T}$ cells and their influence in antibody production in SLE, we studied proliferation of PBMC to purified hnRNP-A2/B1 in SLE patients and healthy controls.

Methods Stimulation assays with PBMC of 34 SLE patients and 21 healthy controls were performed. We then proceeded to draw RA33-specific T cell clones (TCC) by cultivation and limiting-dilution cloning of $\mathrm{T}$ cell lines. 